\title{
Determination of gas-liquid partition coefficients of several organic solutes in trihexyl(tetradecyl)phosphonium bromide using capillary gas chromatography columns
}

\author{
Nicolás R. Ronco, Fiorella Menestrina, Lílian M. Romero*, Cecilia B. Castells* \\ Laboratorio de Investigación y Desarrollo de Métodos Analíticos (LIDMA) and División Química Analítica, Facultad de Ciencias Exactas, UNLP-CIC-CONICET, \\ 47 and 115 (B1900AJL), Argentina
}

\section{A R T I C L E I N F O}

\section{Article history:}

Received 10 March 2017

Received in revised form 20 April 2017

Accepted 21 April 2017

Available online 23 April 2017

\section{Keywords:}

Gas-liquid partition coefficients

Capillary GC columns

Trihexyl(tetradecyl)phosphonium bromide

Interfacial adsorption

\begin{abstract}
A B S T R A C T
In this paper, we report gas-liquid partition constants for thirty-five volatile organic solutes in the room temperature ionic liquid trihexyl(tetradecyl)phosphonium bromide measured by gas-liquid chromatography using capillary columns. The relative contribution of gas-liquid partition and interfacial adsorption to retention was evaluated through the use of columns with different the phase ratio. Four capillary columns with exactly known phase ratios were constructed and employed to measure the solute retention factors at four temperatures between 313.15 and $343.15 \mathrm{~K}$. The partition coefficients were calculated from the slopes of the linear regression between solute retention factors and the reciprocal of phase ratio at a given temperature according to the gas-liquid chromatographic theory. Gas-liquid interfacial adsorption was detected for a few solutes and it has been considered for the calculations of partition coefficient. Reliable solute's infinite dilution activity coefficients can be obtained when retention data are determined by a unique partitioning mechanism. The partial molar excess enthalpies at infinite dilution have been estimated from the dependence of experimental values of solute activity coefficients with the column temperature. A thorough discussion of the uncertainties of the experimental measurements and the main advantages of the use of capillary columns to acquire the aforementioned relevant thermodynamic information was performed.
\end{abstract}

(c) 2017 Elsevier B.V. All rights reserved.

\section{Introduction}

The properties of room temperature ionic liquids (RTILs) have been the focus of a profuse scientific research in recent years since these compounds can be potentially employed in many areas of chemical sciences [1-4]. In particular, their extremely low vapor pressures and thermal stabilities over a wide temperature range makes make them very attractive compounds to replace toxic organic solvents in many analytical-scale and industrial separations. The screening of RTILs that can replace volatile organic compounds can be made through the examination of infinite dilution activity coefficient data of typical solutes in those solvents.

Infinite dilution activity coefficients of different organic compounds in ionic liquids can be measured by inverse gas-liquid chromatography (GLC), i.e., by using the RTIL as the stationary

\footnotetext{
* Corresponding author.

E-mail addresses: 1romero@quimica.unlp.edu.ar (L.M. Romero), castells@isis.unlp.edu.ar (C.B. Castells).
}

phase. This is a well-known method and it has been widely used to determine thermodynamic data of binary mixtures between several compounds and chemically diverse ILs. A few examples are the references [5-13]. The determination of activity coefficients or, either, gas-liquid partition coefficients by dynamic GLC in packed columns is based on the direct measurement of solute retention volume in columns containing an exactly known amount of stationary liquid (the non-volatile IL) at a given temperature. The activity coefficients, partial molar excess free energies, and enthalpy for the solute infinitely diluted in the IL are then easily obtained $[14,15]$. Activity coefficients are usually calculated by using an equation proposed by Everett and Cruickshank for corrections due to interactions between solute vapor molecules with the carrier gas molecules $[16,17]$. These corrections depend on physical properties of the solute and the carrier gas as well as on the pressure drop along the column.

The GLC approach is mature and, then, a classical method. However, it is well-recognized that the retention of those volatile compounds in the GLC column can be a very complex process and under some circumstances other adsorption mechanisms at 
the different interfaces coexist with partitioning into the liquid phase [18-21]. Whenever the aim is the determination of thermodynamic bulk properties, all possible adsorption contribution must be considered. In those situations, the chromatographic retention volumes are determined by the contribution of both the partition into the liquid phase and the adsorption at the interfaces. Packed columns containing high liquid phase loadings are prepared with the aim of minimizing the gas-solid interface adsorption [18,11,22]. The partition coefficient is, thus, mathematically estimated from the retention volumes collected from packed columns containing several stationary phase volumes (see below).

With only few specific exceptions, such as analyses of permanent gases that are frequently better retained with specific supports in packed columns, capillary columns dominate nowadays analytical GC separations. These last columns, however, have less acceptance among researchers for obtaining relevant physicochemical information $[18,23,24]$. The main argument against the capillary format is that some solvents would not form a uniform coating onto the silica walls, especially stationary phases having low viscosity and, even worse if they have high critical surface tension of wetting $[24,25]$. The other reason to disregard capillaries for physicochemical determinations is the difficulty to obtain highly precise retention volumes from the measurements of the low volumetric flow-rates necessary to operate at reasonable linear velocities when using open tube capillaries.

From a theoretical point of view, however, one can advocate that the geometry of wall-coated columns are extremely simple as compared to the irregular surface provided by the porous supports employed in the construction of packed columns. Moreover, a rough estimation of surface areas associated to both column formats reveals more than two orders of magnitude lower surface for a common 20 -m length capillary tube as compared to a typical packed column containing 1 or $2 \mathrm{~g}$ of solid packing. Thus, the significant reduction in surface area in addition to the lack of tortuosity are undoubtedly of paramount importance to reduce all the adsorption contributions at the interfaces.

The aim of this study was to measure gas-liquid partition coefficients of a wide variety of volatile solutes in the RTIL trihexyl(tetradecyl)phosphonium bromide (THTDP-Br) through the use of open tube capillary columns containing different phase ratios. These coefficients were determined at four temperatures between 313.15 and $343.15 \mathrm{~K}$ The solutes included aliphatic and aromatic hydrocarbons, ketones, esters, alcohols, ethers, and other chemically and industrially common solvents. Gas-liquid partition coefficients and infinite dilution activity coefficients are calculated by resorting to simple equations derived from the chromatographic theory. Partial molar excess enthalpies at infinite dilution were finally estimated from the dependence of activity coefficients with the absolute temperature. The experimental methodology used to evaluate the potential contribution from gas-liquid adsorption and verify the quality of those measurements have been critically discussed.

\section{Theory}

The infinite dilution partition coefficient for a solute in the equilibrium between vapor and liquid phases, $K_{L}$, is defined as the ratio between concentrations of the solute in the liquid $\left(C_{L}\right)$ and the gas $\left(C_{g}\right)$ phases at a given temperature, $K_{L}=C_{L} / C_{g}$. Considering that at relatively low pressures, the vapor phase behaves ideally, and that the solute is infinitely diluted in the liquid phase, $K_{L}$ and the solute activity coefficient are related as

$K_{L}=\frac{\mathrm{RT}}{p_{i}^{o} \gamma_{i}^{\infty} v_{L}}$ where $p_{i}^{o}$ and $v_{\mathrm{L}}$ are the solute saturated vapor pressure and the liquid molar volume, respectively, at temperature $\mathrm{T}, \gamma_{i}^{\infty}$ is the solute infinite dilution activity coefficient, and $\mathrm{R}$ is the universal gas constant. The validity of the assumption of ideal vapor phase was checked for a few solutes. Most corrections account from about $1 \%$ at $40^{\circ} \mathrm{C}$ to less than $2 \%$ at $70^{\circ} \mathrm{C}$ respect to the uncorrected values of activity coefficients, which are within the precision of the measurements (data not shown).

In GLC, the solute retention volume is mainly the consequence of the partition process. Additional retention mechanisms, however, would also contribute to retention. These simultaneous processes are mainly due to strong interactions of certain solutes at the gas-liquid interface, and also at the solid-liquid and gas-solid interfaces of any system. Considering all of these contributions, the solute net retention volume, $\mathrm{V}_{\mathrm{N}}$, is described by [18-21]:

$\mathrm{V}_{\mathrm{N}}=K_{L} \mathrm{~V}_{\mathrm{L}}+K_{A} \mathrm{~A}_{\mathrm{L}}+K_{I} \mathrm{~A}_{\mathrm{I}}+K_{S} \mathrm{~A}_{\mathrm{S}}$

where $V_{L}$ is the stationary phase volume, $A_{L}, A_{I}$, and $A_{S}$ represent the surface areas of the gas-liquid, solid-liquid and gas-solid interfaces, respectively; and $K_{A}, K_{I}$ and $K_{S}$ are the adsorption isotherm slopes of the three above-mentioned processes. Deactivation of the solid supports, the use of low surface area packing supports and coatings with high loadings of liquid phases are required to minimize the adsorption at the solid interfaces and, thus, to neglect the last two terms in Eq. (2). The relative contributions between partition and adsorption at the gas-liquid interface can be evaluated by chromatographic retention volume from a set of packed columns containing several liquid loadings. By arrangement of Eq. (2):

$\mathrm{V}_{\mathrm{N}} / \mathrm{V}_{\mathrm{L}}=K_{L}+K_{A} \mathrm{~A}_{\mathrm{L}} / \mathrm{V}_{\mathrm{L}}$

and, a plot of the ratio $V_{N} / V_{L}$ against $1 / V_{L}$ will be close to a straight line if $A_{L}$ does not depend on $V_{L} . K_{L}$ can be calculated from the intercept at $1 / \mathrm{V}_{\mathrm{L}}=0$. If the second term of Eq. (3) is statistically zero, only gas-liquid partition determine the solute retention volume and the ratio $\mathrm{V}_{\mathrm{N}} / \mathrm{V}_{\mathrm{L}}$ would be constant. The second term in Eq. (3), however, can be non-negligible mainly due to two reasons: $i$. systems characterized by significant gas-liquid interfacial adsorption, i.e., $K_{A}$ different from zero, which is often verified for solutes with strong positive deviations from Raoult's law in a given liquid, and $i$. when $A_{L}$ is very large as compared to $V_{L}$, even though adsorption at the interface would be weak.

Considering that solute retention can be measured in either, volume and time scales, by dividing by the hold-up volume, Eq. (2) can be re-written as:

$\mathrm{V}_{\mathrm{N}} / \mathrm{V}_{\mathrm{M}}=\mathrm{t}_{\mathrm{R}} / \mathrm{t}_{\mathrm{M}}-1=K_{L} \mathrm{~V}_{\mathrm{L}} / \mathrm{V}_{\mathrm{M}}+K_{\mathrm{A}} \mathrm{A}_{\mathrm{L}} / \mathrm{V}_{\mathrm{M}}$

where $\mathrm{V}_{\mathrm{M}}$ denotes the column hold-up volume corrected by the gas compressibility, $t_{R}$ and $t_{M}$ are solute retention and hold up times, respectively. Considering that $\mathrm{V}_{\mathrm{N}} / \mathrm{V}_{\mathrm{M}}$ is the retention factor, $\mathrm{k}$, and that $\mathrm{V}_{\mathrm{L}} / \mathrm{V}_{\mathrm{M}}$ is the reciprocal of phase ratio, the following expression can be obtained by including these two concepts in Eq. (4):

$\mathrm{k}=K_{L} / \beta+K_{A} \mathrm{~A}_{\mathrm{L}} / \mathrm{V}_{\mathrm{M}}$

where $\beta$ is the column phase ratio. Provided that the second term is independent of the phase ratio, the partition coefficients can be obtained from the slope of the straight line obtained by representing the retention factor as a function of $1 / \beta$.

\section{Experimental}

\subsection{Instrumentation}

Chromatographic measurements were performed in an HP6890 Plus Agilent gas chromatograph with flame-ionization detector and 
Table 1

Physical properties of the capillary columns.

\begin{tabular}{|c|c|c|c|c|c|c|c|c|}
\hline \multirow[t]{2}{*}{ Column number } & \multirow[t]{2}{*}{ Length (m) } & \multirow[t]{2}{*}{$\mathrm{C}_{\mathrm{o}}{ }^{\mathrm{a}}\left(\mathrm{mg} \mathrm{mL}^{-1}\right)$} & \multicolumn{3}{|c|}{$\mathrm{T}=40^{\circ} \mathrm{C}$} & \multicolumn{3}{|c|}{$\mathrm{T}=70^{\circ} \mathrm{C}$} \\
\hline & & & $\beta$ & $\mathrm{d}_{\mathrm{f}} \mathrm{b}(\mu \mathrm{m})$ & $\mathrm{A}_{\mathrm{L}} / \mathrm{V}_{\mathrm{M}}^{\mathrm{c}}\left(\mathrm{cm}^{-1}\right)$ & $\beta$ & $\mathrm{d}_{\mathrm{f}}(\mu \mathrm{m})$ & $A_{L} / V_{M}\left(\mathrm{~cm}^{-1}\right)$ \\
\hline 1 & 9.0 & 1.74 & 543 & 0.115 & 160.1 & 532 & 0.117 & 160.2 \\
\hline 2 & 7.8 & 4.31 & 218 & 0.285 & 160.4 & 214 & 0.291 & 160.4 \\
\hline 3 & 7.6 & 5.35 & 176 & 0.353 & 160.5 & 172 & 0.361 & 160.5 \\
\hline 4 & 8.1 & 6.93 & 136 & 0.456 & 160.6 & 133 & 0.466 & 160.6 \\
\hline
\end{tabular}

${ }^{a}$ Concentration of the trihexyl(tetradecyl)phosphonium bromide solution at room temperature.

${ }^{\mathrm{b}} \mathrm{d}_{\mathrm{f}}=$ Film thickness.

'Estimated from geometry: $A_{L} / V_{M}=4 /\left(d_{c}-2 d_{f}\right)$, where $d_{c}$ denotes column diameter.

manual-injection port. The data were acquired by means of the software Clarity (DataApex, Czech Republic). Injection port and detector were set at $200^{\circ} \mathrm{C}$ and $220^{\circ} \mathrm{C}$, respectively. Nitrogen was used as carrier gas. A home-made oven, modified from a gas chromatograph, has been used to construct the capillary columns by a static method developed in our laboratory [26].

\subsection{Materials and methods}

Fused silica capillary tubing of $250 \mu \mathrm{m}$ i.d. was provided by MicroQuartz (München, Germany). All the solutes were of analytical-reagent grade and used as received. Sodium chloride was obtained from Anedra (Buenos Aires, Argentina) and the solvents from Merck KGaA (Darmstadt, Germany).

The trihexyl(tetradecyl)phosphonium bromide ( $\left.\left[\mathrm{P}\left(\mathrm{C}_{6} \mathrm{H}_{13}\right)_{3}\left(\mathrm{C}_{14} \mathrm{H}_{29}\right)\right] \mathrm{Br}\right)$, CAS Number 654057-97-3) CYPHOS 102 provided by Cytec (Cytec Industries, NJ, USA), was purified by dissolving the IL in dichloromethane and extracting five times with a $10^{-4} \mathrm{M} \mathrm{KOH}$ solution, followed by extractions with deionized water up to absence of bromide anion in the aqueous phase (tested by precipitation after addition of concentrated solution of silver nitrate). Finally, the IL was thoroughly dried in a vacuum oven at $90^{\circ} \mathrm{C}$. Coating solutions of the IL were prepared in dichloromethane. The concentrations of those solutions are reported in Table 1.

The experimental data of the IL densities at several temperatures were taken from the reference [27]. Those literature values, within the temperature range used in this study, were fitted to the following equation:

$$
\begin{aligned}
& \rho\left(\mathrm{g} \mathrm{cm}^{-1}\right)=1.1371\left( \pm 3 \times 10^{-4}\right)-6.102\left( \pm 9 \times 10^{-3}\right) \\
& \quad \times 10^{-4} T \quad \mathrm{r}^{2}=0.99996
\end{aligned}
$$

where $T$ is the temperature in $\mathrm{K}$.

\subsubsection{Capillary columns construction}

The experimental methodology for column construction has been previously described [28-30] and it will be briefly described here. Before coating with the stationary phase film, a rugged surface containing sodium chloride crystals was formed onto the inner wall by filling the tube with a saturated solution of sodium chloride in methanol, followed by evaporation of the solvent. This procedure was repeated twice and, finally, the capillary was dried for $1 \mathrm{~h}$ under a low flow of nitrogen at $80^{\circ} \mathrm{C}$.

Four columns of different phase ratios were constructed by the static-coating procedure consisting in the evaporation of the coating solvent by a controlled heating of the capillary during the introduction of one open end of the filled coil into the oven at a controlled velocity. The oven temperature was maintained above the solvent boiling point. After evaporation, the columns were conditioned at $100^{\circ} \mathrm{C}$ for $6 \mathrm{~h}$ flushing with a low nitrogen flow. A homogeneous film of stationary phase is attainable by following this procedure. From the stationary phase density, the column phase ratio, $\beta(T)$, can be estimated from geometrical considerations at each temperature from the following expression:

$\beta(T)=\frac{\rho_{\mathrm{s}}(\mathrm{T})}{C_{0}} \exp \left[\alpha_{S i}\left(T-T_{0}\right)\right]-1$

where $\rho_{S}(T)$ is the stationary phase density at temperature $T, C_{0}$ represents the concentration of the IL solution prepared to fill the capillary (expressed as $(\mathrm{w} / \mathrm{v})$ ) at the temperature $T_{0}$, and $\alpha_{S i}$ denotes the thermal expansion coefficient of the silica $[24,28]$. This expression allowed us to calculate reliable column phase ratio provided that the IL solution concentration, $C_{0}$ and density are determined with high precision. The dependence of column phase ratio on temperature is practically equal to that of the stationary phase density. Details on the geometrical characteristics of the constructed columns are given in Table 1.

\subsubsection{Chromatographic measurements}

Gas carrier flow-rate was adjusted to obtain reasonable analysis times. Vapors from the head-space of $1.5-\mathrm{mL}$ vials were injected at least three times in different days. The split ratio was set at 1:10. Retention times were measured at the peak maximum with a precision of $0.001 \mathrm{~min}$ along with the retention of methane, used to estimate the hold-up time. The extra-column volume was considered negligible for the column dimensions used in this work. Measurements for thirty-five solutes in the four columns were performed at four temperatures within the range from 40 to $70^{\circ} \mathrm{C}$.

\section{Results and discussion}

Room temperature ionic liquids (RTILs), mainly $\mathrm{N}$ methylimidazolium and pyrrolidinium salts, have been the subject of numerous and diverse publications emphasizing their physical properties. A number of phosphonium cation-based ILs are also commercially available and have a range of useful properties, but they have been less studied [31]. These studies aimed the search of innovative potential applications for those compounds, and this requires of the knowledge of their physical and thermodynamic properties.

The method here proposed, based on the use of wall-coated columns to determine partition coefficient data of volatile solutes in a non-volatile liquid has been previously tested [29]. As a proof of concept, squalane was chosen as stationary phase in that study, and two chemical families were chromatographed. n-Alkanes allowed to validate the experimental results by comparison with partition coefficient data obtained by different research groups employing either packed columns or other non-chromatographic methods. Then, several $n$-alkanols were chromatographed in those columns at several temperatures. These polar compounds were very challenging since they are characterized by strong adsorption onto the gas-squalane interface. Even though adsorption contribution was very significant, alcohol-squalane partition constants estimated with those columns were in close agreement with data obtained by using a set of packed columns containing different amounts of 


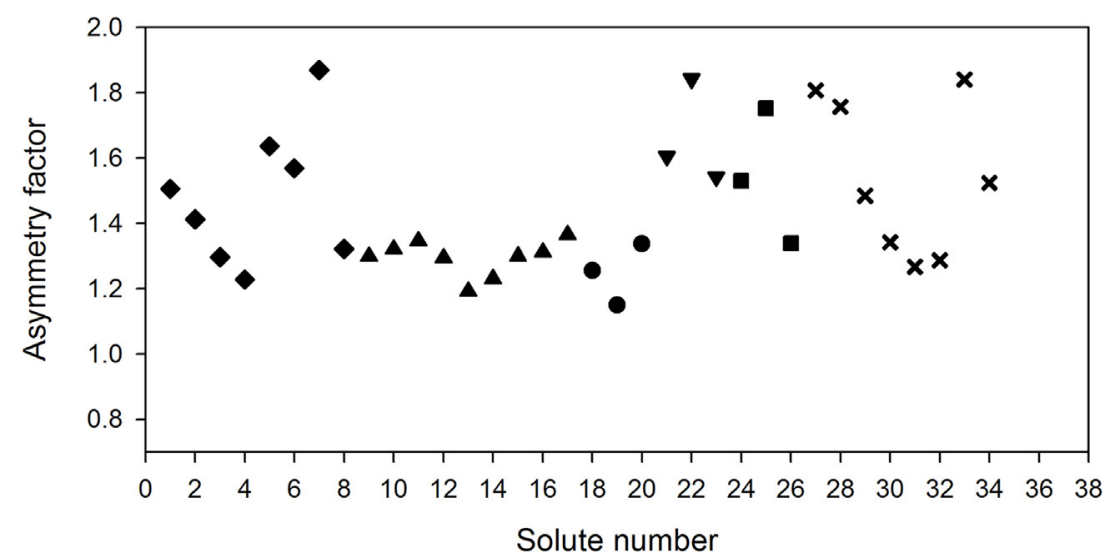

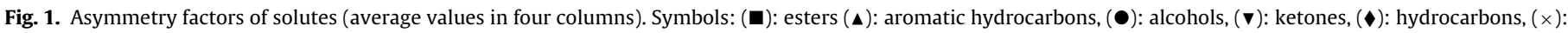
other solvents.

squalane onto Chromosorb P. In the present work, partition coefficients of many different compounds in THTDP-Br coated into capillary tubes, were obtained. To the best of our knowledge, no activity coefficient data are available in the literature involving this phosphonium-based RTIL. In the choice of the IL, we also took into account its very high room temperature viscosity as compared to other RTILs [31], attribute which would contribute to form stable films on the inner wall of the capillary tubes. Since a few studies reporting the use of phosphonium-based IL in open tube GC $[32,33]$ do not provide many details of the silica surface preparation, a procedure similar to that reported for columns containing N-based ILs was followed [33].

Small volumes of vapor samples were injected in order to obtain detectable signals but keeping the solute's infinite dilution conditions. In this situation, asymmetric profiles would indicate adsorption onto liquid-solid and gas-solid interfaces. Thus, firstly, the solute peak profiles were evaluated. Results showed that most peaks exhibited reasonable symmetries even though there are solutes with strong hydrogen-bonding functional groups (alcohols, chlorinated solvents, etc.). Fig. 1 shows the asymmetry factors (an average of the asymmetries observed in all columns) for all the compounds. From these results, especially from the asymmetry factors of alcohols and other very polar compounds that did not exhibit anomalous profiles, it can be inferred that the surface has been fully coated by the IL film preventing adsorption at the solid surface.

Retention factors for each solute in the four columns and at four temperatures were calculated from retention and hold-up times. According to Eq. (5), a linear dependence between retention factors and the reciprocal of phase ratio is expected. The second term on the right of Eq. (5) can be negligible or significantly larger than zero. In this latter case, a linear plot is feasible only if the ratio $A_{L} / V_{M}$ keeps constant and independent of the column phase ratio. From geomet-

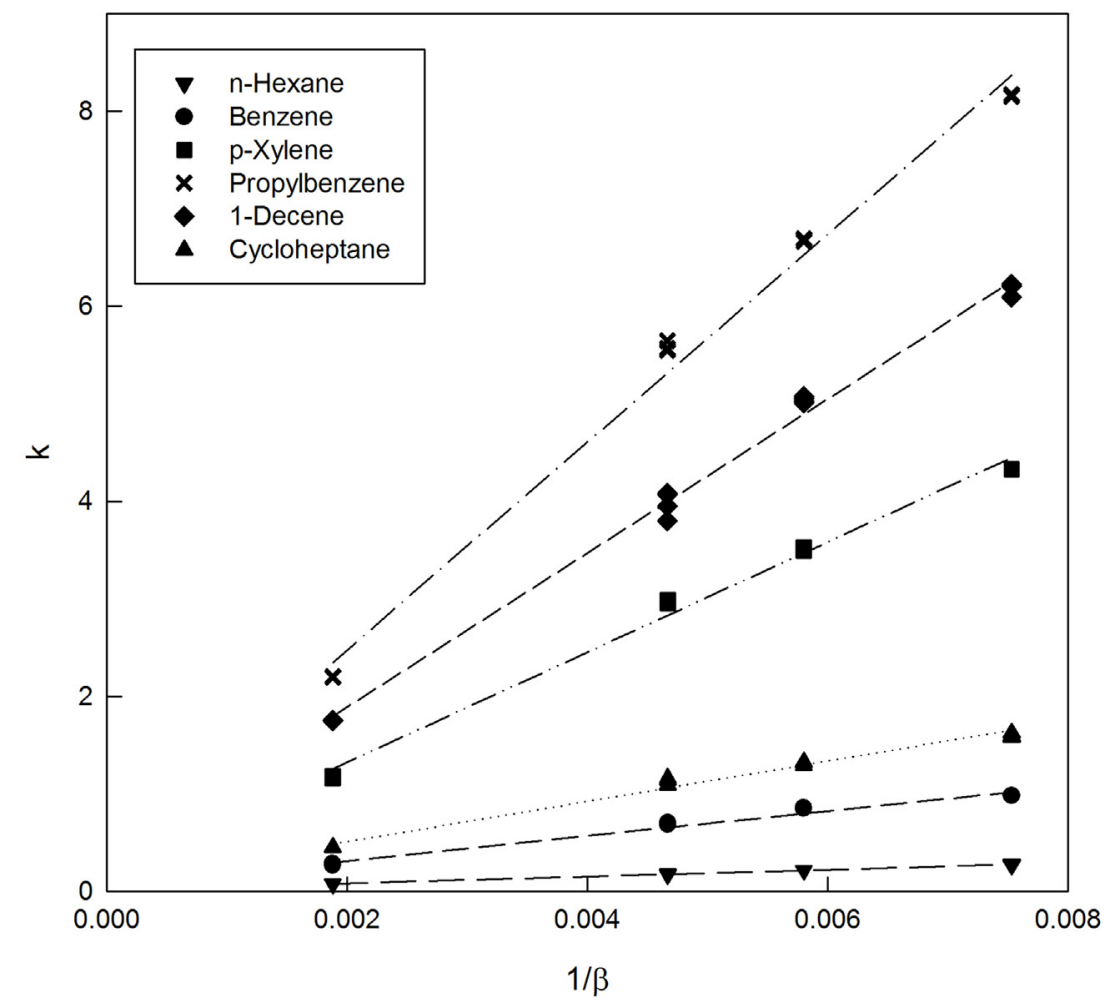

Fig. 2. Retention factors of hydrocarbons as a function of $1 / \beta$ for columns containing trihexyltetradecylphosphonium bromide at $70{ }^{\circ} \mathrm{C}$. 


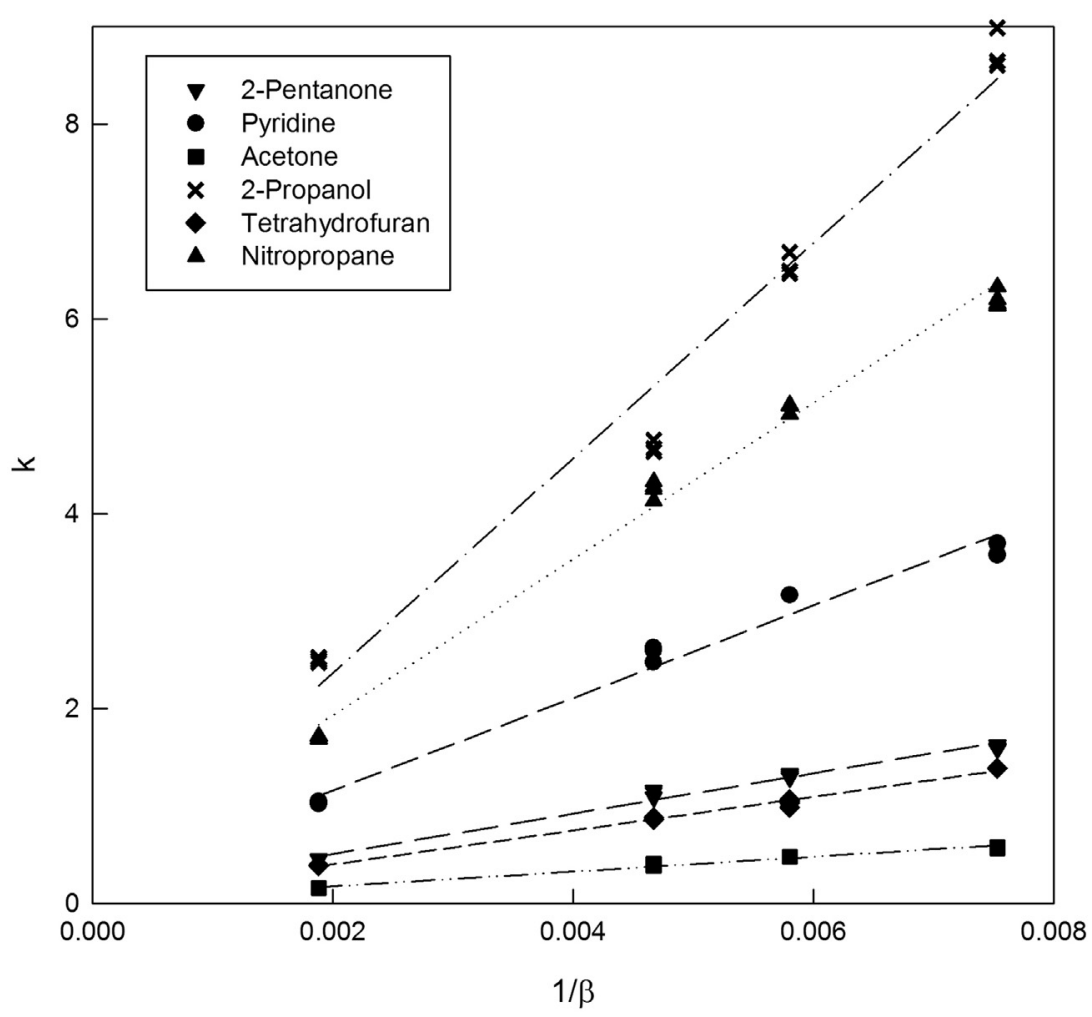

Fig. 3. Retention factors of common chemical solvents as a function of $1 / \beta$ for columns containing trihexyltetradecylphosphonium bromide at $70{ }^{\circ} \mathrm{C}$.

rical calculations and considering a smooth homogeneous coating, this ratio can be calculated for all the columns as $4 /\left(\mathrm{d}_{\mathrm{c}}-2 \mathrm{~d}_{\mathrm{f}}\right)$, where $\mathrm{d}_{\mathrm{c}}$ and $\mathrm{d}_{\mathrm{f}}$ denote the column internal diameter and film thickness, respectively. The estimated values are reported in Table 1 . Within the experimental uncertainties, the $A_{L} / V_{M}$ ratio can be considered constant for columns having phase ratio between about 130 and 550. As a consequence, the partition coefficients, $K_{L}$, are obtained from the slopes computed from the linear regression between the retention factors $v$ s. $1 /{ }^{\circledR}$. Similarly, $K_{A}$ would be calculated from the corresponding intercepts.

Figs. 2 and 3 show the experimental data for a few representative solutes at $70^{\circ} \mathrm{C}$ : aliphatic and aromatic hydrocarbons (Fig. 2) and other chemically common solvents (Fig. 3). A quite linear behavior can be clearly observed in those plots. Table 2 summarizes the least-square linear regression parameters for all the solutes at two temperatures along with the corresponding standard deviations. Clearly, the determination coefficients were very good for some solutes and excellent for others, and similar results were observed at the other studied temperatures.

The intercept values of those regressions were evaluated by a $t$-test analysis. The results suggest that the second term of Eq. (5) is not significantly different from zero with a $p>0.05$ for most of the systems. Only a few solutes at $40^{\circ} \mathrm{C}$ presented a not null intercept. From these results, it can be inferred that, within the experimental errors, partitioning process constitutes practically the unique mechanism of solute retention in this RTIL. This, however, does not necessarily imply that $K_{A}$ is zero; more results would be needed to estimate with higher precision a low $K_{A}$ value or, furthermore, a large increase in the $A_{L} / V_{M}$ ratio would potentially reveal a marginal adsorption contribution. Even though adsorption at all the interfaces would be neglected for most systems, the partition coefficient data collected from four independent columns should be considered very robust and reliable thermodynamic information. In fact, the $K_{L}$ values had relative standard deviations between less than $0.01-0.1$ with a mean value of 0.038 , a quite acceptable precision as compared to values obtained from packed columns.

The introduction of the proposed method to determine gasliquid partition coefficients compelled us to critically discuss its many advantages in comparison with the classical GLC method using packed columns. The most remarkable ones are the following: $i$. the geometrical simplicity of a liquid phase coated as a smooth film onto the inner surface of the capillary tube; $i$. the significantly smaller surface area exposed for adsorption as compared to a liquid phase coated onto the common supports; as a consequence, it is expected that the adsorption contribution to retention would be negligible the even though $K_{A}$ values can be significant; iii. partition coefficients are calculated from the slope of the regression of several independent measurements of retention in different columns, i.e., random potential errors during the column construction would be clearly noted; $i v$. calculations made in time scale are straightforward: it makes not necessary to measure gas carrier flow-rates, neither the inlet and outlet pressures to calculate the compressibility factor; $v$. peaks have narrower bandwidths compared to a packed-column counterpart for a properly prepared fused-silica capillary column, yielding better peak shapes and making feasible to measure accurate time at the peak maximum. In summary, we emphasized that this method provides a very reliable and straightforward way to calculate the relative contributions of partition and adsorption to the solute retention, and it can be applied as a gateway to obtain meaningful partition coefficients.

The activity coefficient data for the studied organic solutes infinite diluted in THTDP-Br at four temperatures are reported in Table 3. The activity coefficient values have the following general order: alkenes $\approx$ alkanes $>$ aromatics $>$ esters $>$ cyclic ethers "alcohols. The obtained data indicate that the IL interact with both non-polar molecules, through dispersive interactions with the long alkyl chains, and with polar molecules, especially solutes with hydrogen bond donors and to a lesser extent with 
Table 2

Results of the least-square regressions for retention factors of solutes with the reciprocal of the phase ratio at $40,50,60$ and $70{ }^{\circ} \mathrm{C}$.

\begin{tabular}{|c|c|c|c|c|c|c|c|c|c|c|}
\hline \multirow[t]{2}{*}{ Solute } & \multicolumn{5}{|l|}{$40^{\circ} \mathrm{C}$} & \multicolumn{5}{|l|}{$70^{\circ} \mathrm{C}$} \\
\hline & Intercept & s.d. & $\mathrm{K}_{\mathrm{L}}$ & s.d. & $\mathrm{R}^{2}$ & Intercept & s.d. & $\mathrm{K}_{\mathrm{L}}$ & s.d. & $\mathrm{R}^{2}$ \\
\hline n-Hexane & 0.035 & 0.008 & 79 & 1 & 0.996 & 0.011 & 0.03 & 35 & 1 & 0.997 \\
\hline n-Heptane & 0.08 & 0.04 & 210 & 7 & 0.986 & 0.05 & 0.03 & 69 & 4 & 0.955 \\
\hline n-Octane & 0.28 & 0.12 & 581 & 23 & 0.993 & 0.03 & 0.06 & 191 & 11 & 0.985 \\
\hline n-Nonane & 0.9 & 0.6 & 1259 & 124 & 0.896 & 0.16 & 0.09 & 366 & 17 & 0.973 \\
\hline n-Decane & 2 & 2 & 3349 & 286 & 0.926 & 0.4 & 0.2 & 817 & 29 & 0.985 \\
\hline 2,2-Dimethyl-pentane & 0.09 & 0.02 & 84 & 4 & 0.971 & 0.029 & 0.019 & 38 & 2 & 0.973 \\
\hline Cyclohexane & 0.13 & 0.02 & 139 & 4 & 0.986 & 0.03 & 0.02 & 69 & 3 & 0.974 \\
\hline Cycloheptane & 0.32 & 0.26 & 577 & 12 & 0.994 & 0.09 & 0.06 & 207 & 6 & 0.989 \\
\hline 1-Octene & 0.32 & 0.02 & 563 & 5 & 0.999 & 0.06 & 0.1 & 185 & 12 & 0.984 \\
\hline 1-Decene & 2.1 & 0.4 & 2995 & 79 & 0.990 & 0.31 & 0.18 & 790 & 14 & 0.995 \\
\hline Benzene & 0.2 & 0.1 & 337 & 22 & 0.951 & 0.06 & 0.03 & 127 & 5 & 0.984 \\
\hline Toluene & 0.4 & 0.2 & 857 & 45 & 0.968 & 0.1 & 0.06 & 284 & 10 & 0.984 \\
\hline Ethylbenzene & 0.5 & 0.3 & 1771 & 61 & 0.984 & 0.3 & 0.11 & 515 & 19 & 0.980 \\
\hline Propylbenzene & 2.3 & 0.6 & 3789 & 123 & 0.983 & 0.3 & 0.14 & 1065 & 26 & 0.993 \\
\hline sec-Butylbenzene & 3.3 & 0.6 & 5634 & 119 & 0.994 & 0.5 & 0.2 & 1525 & 36 & 0.993 \\
\hline Mesitylene & 1.3 & 0.8 & 4449 & 156 & 0.982 & 0.13 & 0.16 & 1232 & 5 & 0.999 \\
\hline o-Xylene & 1.6 & 0.6 & 2461 & 115 & 0.970 & 0.27 & 0.08 & 747 & 16 & 0.993 \\
\hline m-Xylene & 0.9 & 0.4 & 1917 & 49 & 0.990 & 0.20 & 0.07 & 580 & 12 & 0.993 \\
\hline p-Xylene & 0.5 & 0.3 & 1986 & 49 & 0.990 & 0.19 & 0.06 & 565 & 12 & 0.992 \\
\hline Acetone & 0.08 & 0.03 & 107 & 5 & 0.973 & 0.021 & 0.009 & 45 & 2 & 0.983 \\
\hline Butanone & 0.12 & 0.08 & 260 & 14 & 0.965 & 0.05 & 0.02 & 92 & 4 & 0.982 \\
\hline 2-Pentanone & 0.16 & 0.08 & 538 & 17 & 0.984 & 0.05 & 0.02 & 173 & 4 & 0.992 \\
\hline Ethyl acetate & 0.1 & 0.02 & 135 & 4 & 0.989 & 0.02 & 0.01 & 60 & 2 & 0.989 \\
\hline Isopropyl acetate & 0.13 & 0.08 & 205 & 4 & 0.996 & 0.04 & 0.01 & 77 & 2 & 0.987 \\
\hline Isopentyl acetate & 0.9 & 0.6 & 1667 & 34 & 0.995 & 0.24 & 0.09 & 453 & 14 & 0.985 \\
\hline n-Propanol & -5.4 & 1.9 & 18884 & 51 & 0.999 & 1.5 & 0.6 & 2831 & 115 & 0.982 \\
\hline n-Butanol & - & - & - & - & - & -1 & 1 & 6670 & 311 & 0.977 \\
\hline Isopropanol & 3.8 & 2.6 & 4676 & 124 & 0.990 & 0.2 & 0.2 & 1103 & 46 & 0.973 \\
\hline Dichloromethane & 0.3 & 0.1 & 350 & 28 & 0.940 & 0.08 & 0.04 & 136 & 7 & 0.970 \\
\hline Chloroform & 0.5 & 0.1 & 4182 & 33 & 0.999 & 0.7 & 0.3 & 872 & 45 & 0.961 \\
\hline Pyridine & 1 & 0.3 & 1508 & 59 & 0.982 & 0.21 & 0.09 & 475 & 17 & 0.986 \\
\hline Dioxane & -0.11 & 0.07 & 624 & 17 & 0.993 & 0.13 & 0.05 & 160 & 9 & 0.970 \\
\hline Tetrahydrofuran & 0.11 & 0.05 & 176 & 10 & 0.960 & 0.03 & 0.12 & 76 & 2 & 0.989 \\
\hline Nitropropane & 1.1 & 0.14 & 2737 & 26 & 0.999 & 0.3 & 0.101 & 802 & 18 & 0.992 \\
\hline Acetonitrile & 0.28 & 0.09 & 277 & 17 & 0.955 & 0.06 & 0.04 & 123 & 6 & 0.976 \\
\hline
\end{tabular}

proton acceptors. In fact, activity coefficients corresponding to alcohols and chlorinated compounds are very low, indicating an extremely strong interaction of these hydrogen-bonding donors with the phosphonium-IL. This dual capacity makes the THTDP-Br very interesting as stationary phase in practical GLC.

The $\gamma^{\infty}$ i data obtained with THTDP-Br have been compared to values available in the literature for the same solutes in other phosphonium-based IL [7,12,34-37] (see Table 4). The comparison showed similar trends, i.e, interactions of those solutes are very similar practically with independence of the anion chemical nature. Mutelet et al. [37] have also reported very low activity coefficient values for methanol, ethanol, chloroform and dichloromethane in trihexyl(tetradecyl)phosphonium L-lactate and for several aliphatic alcohols, and the same chlorinated solutes studied here in trihexyl(tetradecyl)phosphonium 1-S-(+)-10-camphorsulfonate in the range between 323 and $373 \mathrm{~K}$. On the other hand, for non-polar solutes, the magnitude of the $\gamma^{\infty}{ }_{i}$ values, however, are significantly smaller than the corresponding values for other ILs, such as imidazolium and pyridinium-based ILs [5], which indicates that the hydrocarbon chains increase the solute solubility of the less polar solutes. Thus, similarly to results reported with other phosphonium based ILs, this solvent would have a limited potential for using in industrial solvent separation processes.

The infinite dilution activity coefficients of most solutes decreased as temperature increased. The exceptions were strong hydrogen-bonding donor compounds. The corresponding partial molar excess enthalpies, $H_{i}^{e, \infty}$ may in principle be computed by the Gibbs-Helmholtz function:

$H_{i}^{e, \infty}=R \frac{\partial \ln \gamma_{i}^{\infty}}{\partial(1 / T)}$

and represent the enthalpy change for the transfer of one mole of solute from the (infinitely diluted) ideal solution to the real one. The estimated values from least-square regression of the experimental activity coefficients $\left(\ln \gamma_{i}^{\infty}\right)$ against $1 /$ T were also included in Table 3. The relative standard deviations for these thermodynamic quantities were of relatively poor precision (range between $10-40 \%$, which could in principle be attributed to two factors: the choice of a linear model or to experimental errors. Since the measurements were conducted to only four temperatures, there is no sense to fit our data to other more complex model fitting. In order to test if the number of data points are the limiting of precision, we re-calculated $K_{L}$ values from all $k$ - $\beta$ data pairs (about twelve datapoints) at each temperature and then the corresponding activity coefficient values. These data were fitted according to Eq. (8). The standard deviation for the slopes did not change significantly. As a consequence, $H_{i}^{e, \infty}$ values gathered in Table 4 have only a semiquantitative meaning; precision of the reported $K_{L}$ and $\gamma_{i}^{\infty}$ values is of high quality in terms of chromatographic measurement, but not good enough to calculate highly precise partial molar excess enthalpies. 
Table 3

Infinite dilution activity coefficients of solutes at $40,50,60$ and $70^{\circ} \mathrm{C}$, and partial molar excess enthalpies.

\begin{tabular}{|c|c|c|c|c|c|}
\hline \multirow[t]{2}{*}{ Solute } & \multicolumn{4}{|c|}{ Temperature } & \multirow{2}{*}{$\begin{array}{l}\mathrm{H}_{\mathrm{i}}^{\mathrm{e}, \infty} \\
\left(\mathrm{kJ} \mathrm{mol}{ }^{-1}\right)\end{array}$} \\
\hline & $40^{\circ} \mathrm{C}$ & $50^{\circ} \mathrm{C}$ & $60^{\circ} \mathrm{C}$ & $70^{\circ} \mathrm{C}$ & \\
\hline n-Hexane & 1.483 & 1.358 & 1.334 & 1.272 & 4.3 \\
\hline n-Heptane & 1.686 & 1.852 & 1.669 & 1.680 & 1.0 \\
\hline n-Octane & 1.812 & 1.736 & 1.860 & 1.548 & 3.5 \\
\hline n-Nonane & 2.475 & 2.154 & 2.159 & 2.033 & 5.3 \\
\hline n-Decane & 2.749 & 2.599 & 2.404 & 2.274 & 5.8 \\
\hline 2,2-Dimethylpentane & 1.976 & 1.710 & 1.706 & 1.619 & 5.4 \\
\hline Cyclohexane & 1.276 & 1.176 & 1.004 & 0.938 & 9.7 \\
\hline Cycloheptane & 1.243 & 1.261 & 1.036 & 1.063 & 5.9 \\
\hline 1-Octene & 1.537 & 1.555 & 1.527 & 1.359 & 3.4 \\
\hline 1-Decene & 2.512 & 2.227 & 2.126 & 2.001 & 6.5 \\
\hline Benzene & 0.532 & 0.533 & 0.523 & 0.503 & 1.6 \\
\hline Toluene & 0.646 & 0.642 & 0.639 & 0.608 & 1.6 \\
\hline Ethylbenzene & 0.860 & 0.852 & 0.878 & 0.806 & 1.4 \\
\hline Propylbenzene & 1.040 & 0.928 & 0.978 & 0.888 & 3.8 \\
\hline sec-Butylbenzene & 1.233 & 1.141 & 1.205 & 1.026 & 4.4 \\
\hline Mesitylene & 1.192 & 1.167 & 1.195 & 0.990 & 4.7 \\
\hline o-Xylene & 0.864 & 0.851 & 0.832 & 0.745 & 3.1 \\
\hline m-Xylene & 0.903 & 0.876 & 0.865 & 0.799 & 1.3 \\
\hline p-Xylene & 0.827 & 0.833 & 0.855 & 0.791 & 3.9 \\
\hline Acetone & 0.725 & 0.714 & 0.688 & 0.658 & 2.9 \\
\hline Butanone & 0.692 & 0.716 & 0.724 & 0.688 & -0.2 \\
\hline 2-Pentanone & 0.821 & 0.884 & 0.858 & 0.787 & 1.3 \\
\hline Ethyl acetate & 1.291 & 1.135 & 1.082 & 0.980 & 7.8 \\
\hline Isopropyl acetate & 1.316 & 1.338 & 1.121 & 1.140 & 5.4 \\
\hline Isopentyl acetate & 1.539 & 1.600 & 1.338 & 1.397 & 4.2 \\
\hline n-Propanol & 0.033 & 0.036 & 0.055 & 0.051 & -15.7 \\
\hline n-Butanol & - & 0.052 & 0.056 & 0.053 & 22.4 \\
\hline Isopropanol & 0.066 & 0.067 & 0.067 & 0.054 & 5.2 \\
\hline Dichloromethane & 0.118 & 0.116 & 0.124 & 0.129 & -3.0 \\
\hline Chloroform & 0.022 & - & 0.036 & 0.041 & -18.9 \\
\hline Pyridine & 0.483 & 0.492 & 0.478 & 0.446 & 2.3 \\
\hline Dioxane & 0.656 & 0.698 & 0.885 & 0.828 & -8.4 \\
\hline Tetrahydrofuran & 0.578 & 0.603 & 0.625 & 0.541 & 1.3 \\
\hline Nitropropane & 0.512 & 0.525 & 0.471 & 0.468 & 3.4 \\
\hline Acetonitrile & 0.663 & 0.597 & 0.593 & 0.522 & 6.4 \\
\hline
\end{tabular}

Table 4

Comparison of solute's activity coefficient values in different trihexyl(tetradecyl)phosphonium-based ILs.

\begin{tabular}{|c|c|c|c|c|c|c|c|c|c|c|c|c|}
\hline \multirow[t]{3}{*}{ Solute } & \multicolumn{12}{|c|}{ Anion/T $\left({ }^{\circ} \mathrm{C}\right)$} \\
\hline & (a) & (a) & (b) & (c) & (c) & (d) & (e) & (f) & (g) & $40^{\circ} \mathrm{C}$ & This work & $70^{\circ} \mathrm{C}$ \\
\hline & 40 & 60 & 40 & 49.2 & 69.2 & 45 & 45 & 50 & 50 & & $50^{\circ} \mathrm{C}$ & \\
\hline n-Hexane & 1.4 & 1.38 & 0.73 & 1.04 & 1.01 & 0.64 & 0.753 & 1.11 & 1.05 & 1.483 & 1.358 & 1.272 \\
\hline n-Heptane & 1.58 & 1.56 & 0.81 & 1.22 & 1.19 & 0.72 & 0.803 & 1.22 & 1.14 & 1.686 & 1.852 & 1.680 \\
\hline n-Octane & 1.79 & 1.77 & 0.85 & 1.42 & 1.40 & 0.80 & 0.821 & 1.37 & 1.24 & 1.812 & 1.736 & 1.548 \\
\hline n-Nonane & 2.06 & 1.98 & & 1.8 & 1.74 & & & 1.67 & 1.50 & 2.475 & 2.154 & 2.033 \\
\hline n-Decane & 2.38 & 2.26 & & 1.89 & 1.84 & & & 1.67 & 1.52 & 2.749 & 2.559 & 2.274 \\
\hline Cyclohexane & 0.975 & 0.941 & 0.54 & 0.78 & 0.75 & 0.48 & 0.627 & 0.77 & 0.69 & 1.276 & 1.176 & 0.938 \\
\hline Cycloheptane & 1.02 & 0.986 & 0.58 & 1.81 & 3.59 & 0.52 & 0.753 & & & 1.243 & 1.261 & 1.063 \\
\hline Benzene & 0.41 & 0.425 & 0.48 & 0.39 & 0.39 & 0.19 & 0.403 & 0.38 & 0.36 & 0.532 & 0.533 & 0.503 \\
\hline Toluene & 0.526 & 0.531 & & 0.46 & 0.47 & & & 0.46 & 0.41 & 0.646 & 0.642 & 0.608 \\
\hline Ethylbenzene & 0.66 & 0.671 & & 0.57 & 0.59 & & & 0.56 & 0.49 & 0.860 & 0.852 & 0.806 \\
\hline Butanone & 0.444 & 0.447 & & 0.27 & 0.23 & & & & 0.43 & 0.692 & 0.716 & 0.688 \\
\hline 2-Pentanone & & & & 0.32 & 0.33 & & & 0.60 & 0.52 & 0.821 & 0.884 & 0.787 \\
\hline Dioxane & & & & 0.49 & 0.48 & & & & 0.52 & 0.656 & 0.698 & 0.828 \\
\hline n-Propanol & & & & 1.21 & 1 & 1 & & & 0.09 & 0.033 & 0.035 & 0.051 \\
\hline n-Butanol & & & & 1.26 & 1.04 & & & & 0.09 & - & 0.052 & 0.031 \\
\hline i-Propanol & & & & 1.22 & 0.99 & & & & 0.12 & 0.066 & 0.067 & 0.054 \\
\hline Dichloromethane & & & & 0.25 & 0.27 & & & 0.06 & 0.09 & 0.118 & 0.116 & 0.129 \\
\hline Chloroform & & & & 0.31 & 0.32 & & & 0.05 & 0.05 & 0.022 & - & 0.041 \\
\hline Acetonitrile & & & & 0.5 & 0.46 & & & 0.45 & 0.46 & 0.663 & 0.597 & 0.522 \\
\hline Nitropropane & & & & 1.62 & 1.35 & & & 0.33 & 0.35 & 0.512 & 0.525 & 0.468 \\
\hline Pyridine & & & & 0.41 & 0.34 & & & 0.34 & 0.32 & 0.483 & 0.492 & 0.446 \\
\hline Acetone & 0.431 & 0.432 & & & & & & & & 0.725 & 0.714 & 0.658 \\
\hline
\end{tabular}

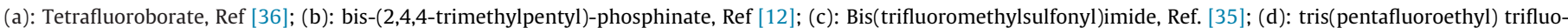
rophosphate, Ref. [7]; (e): Chloride, Ref. [34]; (f): L-Lactate, Ref. [37]; (g) 1-S-(+)-10-Camphorsulfonate, Ref. [37]. 


\section{Conclusions}

Open-tube capillary columns coated with the ionic liquid trithexyl(tetradecyl)phosphonium bromide were successfully used for obtaining infinite dilution partition coefficients of several solutes at four temperatures. Experimentally, solute infinite dilution partition coefficients at a given temperature were calculated from the chromatographic retention in several columns of different and well-known phase ratio and by using simple and well-known chromatographic equations. The capillary columns proved to be geometrically simple and reliable to obtain solute partition coefficient data from true independent systems minimizing errors related to the amount of liquid inside the columns. This approach allows to evaluate the potential gas-liquid interfacial adsorption, which is rather common for systems characterized by strong positive deviations from Raoult's law. Since significant errors on infinite dilution activity coefficients can be made by neglecting adsorption contributions, the construction of a database in which these errors can be minimized can be uniquely valuable.

\section{Acknowledgements}

Financial support from the Agencia Nacional de Promoción Científica y Tecnológica (ANPCYT-PICT 2014-3597), Consejo Nacional de Investigaciones Científicas y Técnicas (CONICET) (PIP-0244), Comisión de Investigaciones Científicas (CIC-PBA) and Universidad Nacional de La Plata is acknowledged.

\section{References}

[1] T. Welton, Room-Temperature ionic liquids. Solvents for synthesis and catalysis, Chem. Rev. 99 (1999) 2071-2083.

[2] R.D. Rogers, K.R. Seddon, Ionic Liquids as Green Solvents: Progress and Prospects, American Chemical Society, Washington, D.C, 2003.

[3] K.R. Seddon, Ionic liquids: designer solvents for green synthesis, Chem. Eng. 730 (2002) 33-35.

[4] N.V. Plechkova, K.R. Seddon, Applications of ionic liquids in the chemical industry, Chem. Soc. Rev. 37 (2008) 123-150.

[5] L.-S. Wang, X.-X. Wang, Y. Li, K. Jiang, X.-Z. Shao, C.-J. Du, Ionic liquids: solubility parameters and selectivities for organic solutes, AIChe 59 (2013) 3034-3041.

[6] F. Mutelet, V. Butet, J.-N. Jaubert, Application of Inverse Gas chromatography and Regular Solution Theory for characterization of ionic liquids, Ind. Eng. Chem. Res. 44 (2005) 4120-4127.

[7] T.M. Letcher, P. Reddy, Determination of activity coefficients at infinite dilution of organic solutes in the ionic liquid, trihexyl(tetradecyl)phosphonium tris(pentafluoroethyl) trifluorophosphate, by gas?liquid chromatography, Fluid Phase Equil. 235 (2005) 11-17.

[8] U. Domanska, A. Marciniak, Activity coefficients at infinite-dilution measurements for organic solutes and water in the 1-hexyloxymethyl-3-methyl-imidazolium and 1, 3- dihexyloxymehtylimidazolium bis9trifluoromethylsulfonyl)-imide ionic liquids. The cation influence, Fluid Phase Equil. 286 (2009) 154-161.

[9] Z.S. Breitbach, D.W. Armstrong, Characterization of phosphonium ionic liquids through a linear solvation energy relationship and their use as GLC stationary phases, Anal. Bioanal. Chem. 390 (2008) 1605-1617.

[10] W.E. Acree Jr., G.A. Baker, A.-L. Revelli, J. -Ch. Moise, F. Mutelet, Activity coefficients at infinite dilution for organic compounds dissolved in 1-Alkyl-1-methylpyrrolidinium Bis(trifluoromethylsulfonyl)imide ionic liquids having six-, eight-, and ten-carbon alkyl chains, J. Chem. Eng. Data 57 (2012) 3510-3518.

[11] J. Kan, L.-S. Wang, X.-X. Wang, J.-D. Duan, Activity coefficients of organic solutes at infinite dilution in the ionic liquids. 2. Organic $s$ in 1-hexyl-3-methylimidazolium nitrate and gas-liquid partitioning and interfacial adsorption using gas-liquid chromatography, Ind. Eng. Chem. Res. 51 (2012) 12479-12487.

[12] T.M. Letcher, D. Ramjugernath, M. Laskowska, M. Krolikowski, P. Naidoo, U. Domanska, Activity coefficients at infinite-dilution measurements for organic solutes in the ionic liquid trihexyltetradecylphosphonium-bis-(2,4,4-trimethylpentyl)-phosphinate using g. l. c. at $\mathrm{T}=(303.15,308.15,313.15$, and 318.15$) \mathrm{K}, \mathrm{J}$. Chem. Thermodyn. 40 (2008) 1243-1247.
[13] A. Ch. Baelhadj, F. Mutelet, B. Jiang, W.E. Acree Jr., Activity coefficients at infinite dilution for organic solutes dissolved in two 1,2,3-tris(diethylamino)cyclopenylium based room temperature ionic liquids, J. Mol. Liq. 223 (2016) 89-99.

[14] J.R. Conder, C.L. Young, Physicochemical Measurements by Gas Chromatography, Wiley, New York, 1979.

[15] C.F. Poole, The Essence of Chromatography, Elsevier, Amsterdam, 2003.

[16] D.H. Everett, Effect of gas imperfection on GLC measurements: a refined method for determining activity coefficients and second virial coefficients, Trans. Faraday Soc. 61 (1965) 1637-1639.

[17] A.J.B. Cruickshank, M.L. Windsor, C.L. Young, The use of gas-liquid chromatography to determine activity coefficients and second virial coefficients of mixture. I. Theory and verification of method of data analysis, Proc. R. Soc. Lond. A 295 (1966) 259-270.

[18] C.F. Poole, Chromatographic and spectroscopic methods for the determination of solvent properties of room temperature ionic liquids, Review. J. Chromatogr. A 1037 (2004) 49-82.

[19] R.L. Martin, Adsorption on the liquid phase in gas chromatography, Anal. Chem. 33 (1963) 347-352.

[20] J.R. Conder, D.C. Locke, J.H. Purnell, Concurrent solution and adsorption phenomena in chromatography. I, J. Phys. Chem. 73 (1969) 700-708.

[21] J.A. Jonsson, L. Mathiasson, Chromatographic Theory Basic Principles, Marcel Dekker, New York, 1987.

[22] L. Marcinkowski, A. Kloskowski, J. Namiesnik, Measurement of activity coefficients at infinite dilution of organic solutes in the ionic liquid 1-hexyl-1,4-diaza[2. 2. 2]bicyclooctanium bis(trifluoromethylsulfonyl)imide using gas?liquid chromatography, J. Chem. Thermodyn. 71 (2014) 84-90.

[23] F.R. González, Application of capillary gas chromatography to studies on solvation thermodynamics, J. Chromatogr. A 1037 (2004) 233-253.

[24] R.C. Castells, Determination of gas-liquid partition coefficients by gas chromatography, J. Chromatogr. A 1037 (2004) 223-231.

[25] W.A. Sizman, Surface energetics of wetting spreading, and adhesion, J. Paint Technol. 44 (1972) 41-57.

[26] F.R. González, J. Pérez-Parajón, J.A. García-Domínguez, Effects of solvent density on retention in gas?liquid chromatography I. Alkanes solutes in polyethylene glycol stationary phases, J. Chromatogr. A 953 (2002) 151-163.

[27] C.M.S.S. Neves, P.J. Carvalho, M.G. Freire, J.A.P. Couthinho, Thermophysical properties of pure and water-saturated tetradecyltrihexylphosphonium-based ionic liquids, J. Chem. Thermodyn. 43 (2011) 948-957.

[28] F.R. González, L.M. Romero, Retention in overloaded columns, an experimental approach, J. Chromatogr. A 1128 (2006) 203-207.

[29] M. Tascon, L.M. Romero, A. Acquaviva, S. Keunchkarian, C.B. Castells, Determinations of gas?liquid partition coefficients using capillary chromatographic columns. Alkanols in squalane, J. Chromatogr. A 1294 (2013) 130-136.

[30] F. Menestrina, N. Ronco, C.B. Castells, Enantioselective gas chromatography with functionalized cyclodextrins as chiral selectors. Fundamentals of the measurement of absolute association constants using capillary columns, J. Chromatogr. A 1467 (2016) 482-489.

[31] J. Fraser, D.R. MacFarlane, Phosphonium-based ionic liquids: an overview, Aust. J. Chem. 62 (2009) 309-321.

[32] C.F. Poole, N. Lenca, Gas chromatography on wall-coated open-tubular columns with ionic liquid stationary phases, J. Chromatogr. A 1357 (2014) 87-109.

[33] M.V. Shashkov, V.N. Sidel'nikov, Single cation ionic liquids as high polarity thermostable stationary liquid phases for capillary chromatography, Russ. J. Phys. Chem. 86 (2012) 138-141.

[34] T. Banerjee, A. Khanna, Infinite dilution activity coefficients for trihexyltetradecyl phosphonium ionic liquids: measurements and COSMO-RS prediction, J. Chem. Eng. Data 51 (2006) 2170-2177.

[35] A.-L. Revelli, L.M. Sprunger, J. Gibbs, W.E. Acree, Jr., G.A. Baker, F. Mutelet, Activity coefficients at infinite dilution of organic compounds in trihexyl(tetradecyl)phosphonium bis(trifluoromethylsulfonyl)imide using inverse gas chromatography, J. Chem. Eng. Data 54 (2009) 977-985.

[36] K. Tumba, P. Reddy, P. Naidoo, D. Ramjugernath, Activity coefficients at infinite-dilution of organic solutes in the ionic liquid trihexyl(tetradecyl)phosphonium tetrafluoroborate using gas-liquid chromatography at $\mathrm{T}=(313.15333 .15,353.15$, and 373.15) K, J. Chem. Therm. 43 (2011) 670-676.

[37] F. Mutelet, D. Alonso, T.W. Stephens, W.E. Acree, Jr., G.A. Baker, Infinite dilution activity coefficients of solutes dissolved in two trihexyl(tetradecyl)phosphonium ionic liquids, J. Chem. Eng. Data 59 (2014) 1877-1885. 